\title{
Retraction
}

\section{Retracted: Corrosion Inhibition of Tubing Steel during Acidization of Oil and Gas Wells}

\author{
Journal of Petroleum Engineering \\ Received 13 November 2018; Accepted 13 November 2018; Published 10 March 2019 \\ Copyright (c) 2019 Journal of Petroleum Engineering. This is an open access article distributed under the Creative Commons \\ Attribution License, which permits unrestricted use, distribution, and reproduction in any medium, provided the original work is \\ properly cited.
}

Journal of Petroleum Engineering has retracted the article titled "Corrosion Inhibition of Tubing Steel during Acidization of Oil and Gas Wells" [1]. The article was found to contain images reused in several other articles published by Mahendra Yadav and colleagues. The details of the reuse of images are as follows: key.

Figure 2 is similar to Figure 3 in [2], with a different figure

Figure 5 is similar to Figure 11 in [3] and Figure 6 in [2], with different figures keys.

Figure 7 is similar to Figure $1 \mathrm{~A}$ in [4], with a different figure key. key.

Figure 4 is similar to Figure 4 in [5], with a different figure

Figure 11(a) is similar to Figure 14a in [2], Figure 5a in [4], Figure 11a in [5], and Figure 9a in [6]. Figure 11(b) is similar to Figure $14 \mathrm{~b}$ in [2], Figure $17 \mathrm{~b}$ in [3], Figure 5b in [4], and Figure $9 \mathrm{~b}$ in [7]. Figure 11(c) is similar to Figure $14 \mathrm{c}$ in [2], Figure 17c in [3], and Figure $9 \mathrm{c}$ in [7]. Figure 11(d) is similar to Figure 14d in [2] and Figure 17d in [3]. In particular, Figure 11 in [1] shares the same image of a sample in $\mathrm{HCl}$ as Figure 9 in [7] and the same image in the presence of an inhibitor, but these represent different inhibitors in each article, BAL and AMPT, respectively.

We asked the authors to provide the underlying uncropped and unadjusted scanning electron microscopy (SEM) images, the raw data, and details of how the experiments were conducted.

The corresponding author, Dr. Yadav, said the SEM work was outsourced but did not give details on where, when, or by whom this work was performed. The equipment is not described in this article. However, it is described as a "JEOL JSM-6380 LA analytical scanning electron microscope" in [7], and in [6] it is described as a "Scanning Electron Microscope model SEM Jeol JSM-5800." These are not the same models of microscope, despite these articles sharing some of the same SEM images.
Dr. Yadav provided us with replacement figures. However, they were identical to two of the articles, [6] and [7], despite representing experiments with the inhibitors AMPT and ODAEODI, respectively. We were not told how these images were generated, the images were of low resolution, and the text in the images was illegible.

The corresponding author agreed to retraction and we have asked the institution to formally investigate.

\section{References}

[1] M. Yadav, Sumit Kumar, and P. N. Yadav, "Corrosion inhibition of tubing steel during acidization of oil and gas wells," Journal of Petroleum Engineering, vol. 2013, Article ID 354630, 9 pages, 2013.

[2] M. Yadav, U. Sharma, and P. Yadav, "Corrosion inhibitive properties of some new isatin derivatives on corrosion of N80 steel in $15 \% \mathrm{HCl}$,' International Journal of Industrial Chemistry, vol. 4, no. 1, p. 6, 2013.

[3] M. Yadav, U. Sharma, and P. N. Yadav, "Isatin compounds as corrosion inhibitors for N80 steel in 15\% HCl," Egyptian Journal of Petroleum, vol. 22, no. 3, pp. 335-344, 2013.

[4] M. Yadav, P. N. Yadav, and U. Sharma, "Substituted imidazoles as corrosion inhibitors for N80 steel in hydrochloric acid," Indian Journal of Chemical Technology, vol. 20, no. 6, pp. 363-370, 2013.

[5] M. Yadav, S. Kumar, U. Sharma, and P. N. Yadav, "Substituted amines as corrosion inhibitors for N80 steel in 15\%HCL," Journal of Materials and Environmental Science, vol. 4, no. 5, pp. 691-700, 2013.

[6] M. Yadav, Sumit Kumar, and P. N. Yadav, "Development of ecofriendly corrosion inhibitors for application in acidization of petroleum oil well," Journal of Chemistry, vol. 2013, Article ID 618684, 9 pages, 2013.

[7] M. Yadav, Sumit Kumar, and Debasis Behera, "Inhibition effect of substituted thiadiazoles on corrosion activity of N80 Steel in HCl solution," Journal of Metallurgy, vol. 2013, Article ID 256403, 14 pages, 2013. 


\title{
Corrosion Inhibition of Tubing Steel during Acidization of Oil and Gas Wells
}

\author{
M. Yadav, ${ }^{1}$ Sumit Kumar, ${ }^{1}$ and P. N. Yadav $^{2}$ \\ ${ }^{1}$ Department of Applied Chemistry, Indian School of Mines, Dhanbad 826004, India \\ ${ }^{2}$ Department of Physics, Post Graduate College, Ghazipur 233001, India
}

Correspondence should be addressed to M. Yadav; yadav_drmahendra@yahoo.co.in

Received 13 September 2012; Accepted 14 November 2012

Academic Editor: Jorge Ancheyta

Copyright (C) 2013 M. Yadav et al. This is an open access article distributed under the Creative Commons Attribution License, which permits unrestricted use, distribution, and reproduction in any medium, provided the original work is properly cited.

Acidization is an oil reservoir stimulation technique for increasing oil well productivity. Hydrochloric acid is used in oil and gas production to stimulate the formation. The acid treatment occurs through N80 steel tubes. The process requires a high degree of corrosion inhibition of tubing material (N80 steel). In the present investigation effect of synthesized amino acid compounds, namely, acetamidoleucine (AAL) and benzamidoleucine (BAL) as corrosion inhibitors for $\mathrm{N} 80$ steel in 15\% $\mathrm{HCl}$ solution was studied by polarization, AC impedance (EIS), and weight loss measurements. It was found that both the inhibitors were effective inhibitors and their inhibition efficiency was significantly increased with increasing concentration of inhibitors. Polarization curves revealed that the studied inhibitors represent mixed type inhibitors. AC impedance studies revealed that charge transfer resistance increases and double layer capacitance decreases in presence of inhibitors. Adsorption of inhibitors at the surface of N80 steel was found to obey Langmuir isotherm.

\section{Introduction}

Acidization of a petroleum oil well is one of the important stimulation techniques for enhancing oil production. It is commonly brought about by forcing a solution of $15 \%$ to $28 \%$ hydrochloric acid into the well through N80 tubing to open up near bore channels in the formation and hence to increase the flow of oil. To reduce the aggressive attack of the acid on tubing and casing materials (N80 steel), inhibitors are added to the acid solution during the acidifying process. The effective acidizing inhibitors that are usually found in commercial formulations are acetylenic alcohols, alkenyl phenones, aromatic aldehydes, nitrogen-containing heterocyclics, quaternary salts, and condensation products of carbonyls and amines [1-6]. However, these inhibitors are effective only at high concentrations, and they are harmful to the environment due to their toxicity, so it is important to search for new nontoxic and effective organic corrosion inhibitors for $\mathrm{N} 80$ steel $-15 \% \mathrm{HCl}$ system. In this regard, amino acids have a promising alternative for the design of ecofriendly corrosion inhibitors [7-10] which satisfy the environmental requirements.
In the present investigation acetamidoleucine (AAL) and benzamidoleucine (BAL) were synthesized, and their corrosion inhibiting properties on N80 (oil-well tubular steel) steel was studied in $15 \% \mathrm{HCl}$ by using weight loss, polarization, and $\mathrm{AC}$ impedance techniques. Influence of temperature (from 298 to $333 \mathrm{~K}$ ) on the inhibition behavior was studied. Both the activation and thermodynamic parameters governing the corrosion process were calculated and discussed.

\section{Material and Methods}

2.1. Materials. The working electrode and specimens for weight loss experiments were prepared from N80 steel sheets (supplied by ONGC) having the following percentage by weight (\%wt) composition: C: 0.31, Mn: 0.92, Si: 0.19, P: 0.01, S: 0.008 , Cr: 0.20 , and Fe: remainder.

2.2. Weight Measurements. The specimens for the weight loss experiments were of the size $3 \mathrm{~cm} \times 3 \mathrm{~cm} \times .1 \mathrm{~cm}$, and for electrochemical studies the exposed surface area of the working electrode was $1 \mathrm{~cm}^{2}$. For weight loss experiments 
$300 \mathrm{~mL}$ of $15 \% \mathrm{HCl}(\mathrm{v} / \mathrm{v})$ was taken in $500 \mathrm{~mL}$ glass beakers. The inhibition efficiencies (IE) were evaluated after a preoptimized time interval of $6 \mathrm{~h}$ using 10,20,50,100, and $150 \mathrm{ppm}$ by weight of inhibitors. The specimens were removed from the electrolyte, washed thoroughly with distilled water, dried, and weighed. The inhibition efficiencies (IE) were calculated using the following equation:

$$
\% \mathrm{IE}=\left[\frac{\mathrm{CR}_{0}-\mathrm{CR}_{i}}{\mathrm{CR}_{0}}\right] \times 100,
$$

where $\mathrm{CR}_{0}$ is the weight loss in absence of inhibitor, and $\mathrm{CR}_{i}$ is the weight loss in presence of inhibitor.

Corrosion rate (CR) for the specimen was calculated with the help of the following equation:

$$
\mathrm{CR}(\mathrm{mpy})=\frac{534 W}{\mathrm{DAT}},
$$

where $W=$ weight loss (mg); $D=$ density of specimen $\left(\mathrm{g} / \mathrm{cm}^{3}\right) ; A=$ area of specimen $\left(\mathrm{cm}^{2}\right) ; T=$ exposure time (hours).

2.3. Adsorption Isotherms. The information about the electrochemical interaction of inhibitors with metal surface can be provided by the nature of adsorption isotherm. Different adsorption isotherm such as Langmuir, Temkin, and Frumkin, were tested graphically by ploting surface coverages $(\theta)$ and concentration of studied (AAL and BAL) on N80 steel in $\mathrm{HCl}$ solution. The surface coverage was calculated using the following equation:

$$
\theta=\left[\frac{\mathrm{CR}_{0}-\mathrm{CR}_{i}}{\mathrm{CR}_{0}}\right] \times 100,
$$

where $\mathrm{CR}_{0}$ is the weight loss in absence of inhibitor, and $\mathrm{CR}_{i}$ is the weight loss in presence of inhibitor.

2.4. Electrochemical Polarization Studies. The electrochemical studies were performed in a three necked glass assembly containing $150 \mathrm{~mL}$ of the electrolyte with different concentrations of inhibitors $(10,50$, and $150 \mathrm{ppm}$ by weight) dissolved in it. The potentiodynamic polarization studies were carried out with N80 steel strips having an exposed area of $1 \mathrm{~cm}^{2}$. A conventional three electrode cell consisting of N80 steel as working electrode, platinum as counter electrode, and a saturated calomel electrode as reference electrode were used. Polarisation studies were carried out using VoltaLab 10 electrochemical analyser, and data was analysed using Voltamaster 4.0 software. The potential sweep rate was $10 \mathrm{mVs}^{-1}$. All experiments were performed at $25 \pm 0.2^{\circ} \mathrm{C}$ in an electronically controlled air thermostat. For calculating inhibition efficiency by electrochemical polarization method, the following formula was used:

$$
\% \mathrm{IE}=\left[\frac{I_{0}-I_{\mathrm{inh}}}{I_{0}}\right] \times 100,
$$

where $I_{0}$ is corrosion current in absence of inhibitor, and $I_{\mathrm{inh}}$ is the corrosion current in presence of inhibitor.
2.5. AC Impedance Studies. AC impedance studies were carried out in a three electrode cell assembly using computercontrolled VoltaLab 10 electrochemical analyzer, as well as N80 steel as the working electrode, platinum as counter electrode, and saturated calomel as reference electrode. The data were analysed using Voltamaster 4.0 software. The electrochemical impedance spectra (EIS) were taken in the frequency range from $10 \mathrm{kHz}$ to $1 \mathrm{mHz}$ at the rest potential by applying $5 \mathrm{mV}$ sine wave $\mathrm{AC}$ voltage. The charge transfer resistance $\left(R_{\mathrm{ct}}\right)$ and double layer capacitance $\left(C_{\mathrm{dl}}\right)$ were determined from Nyquist plots. The inhibition efficiencies were calculated from charge transfer resistance values by using the following formula:

$$
\% \mathrm{IE}=\left[\frac{R_{\mathrm{ct}(\mathrm{inh})}-R_{\mathrm{ct}}}{R_{\mathrm{ct}(\mathrm{inh})}}\right] \times 100,
$$

where $R_{\mathrm{ct}}$ is the charge transfer resistance in absence of inhibitor, and $R_{\mathrm{ct}(\mathrm{inh})}$ is the charge transfer resistance in presence of inhibitor.

2.6. Synthesis of Inhibitors. One gram of leucine was dissolved in $25 \mathrm{~mL}$ of $5 \% \mathrm{NaOH}$ solution in a conical flask. To this mixture benzoyl chloride/acetyl chloride $(2.25 \mathrm{~mL})$ was added in five portions in $(0.49 \mathrm{~mL}$ increments) and shaken vigorously until all the chloride has reacted. Acidified with diluted hydrochloric acid the crude product was washed with cold ether. Finally, the desired product was recrystallized from ethanol [11]. The purity of the compounds was checked by TLC. The structure of the inhibitors are given in Scheme 1 .

\section{Results}

3.1. Weight-Loss Study. Weight-loss studies were performed in accordance with ASTM method. Test was conducted in $15 \% \mathrm{HCl}(\mathrm{v} / \mathrm{v})$ solution for $6 \mathrm{~h}$ at different temperatures (from 298 to $333 \mathrm{~K}$ ) containing different concentration of inhibitors (10-150 ppm).

3.1.1. Effect of Concentration. The percentage inhibition efficiencies (\%IEs) in presence of 10, 20,50, 100, and $150 \mathrm{ppm}$ of AAL and BAL have been evaluated by weight-loss technique at $25^{\circ} \mathrm{C}$, and the results are summarized in Table 1 . It is evident from these values that the inhibitor is significantly effective even at low concentrations like $10 \mathrm{ppm}$ and there is a linear increase in \%IE in the whole range of concentrations studied. The corrosion rate decreases with an increase in concentration of each inhibitor and reached the maximum value in the range of $150 \mathrm{ppm}$ concentration (Figure 1).

3.1.2. Effect of Temperature. The effect of temperature on the performance of AAL and BAL as corrosion inhibitors for $\mathrm{N} 80$ steel in $15 \% \mathrm{HCl}$ was investigated by weight loss measurements in the temperature range $298-333 \mathrm{~K}$ in absence and presence of both the inhibitors at optimum concentration $(150 \mathrm{ppm})$ in a thermostat. The variation of inhibition efficiency and corrosion rate with temperature are shown 
<smiles>CC(=O)NN[C@@H](CC(C)C)C(=O)O</smiles>

Acetamidoleucine<smiles>CC(C)C[C@H](NNC(=O)c1ccccc1)C(=O)O</smiles>

Benzamidoleucine

SCHEME 1

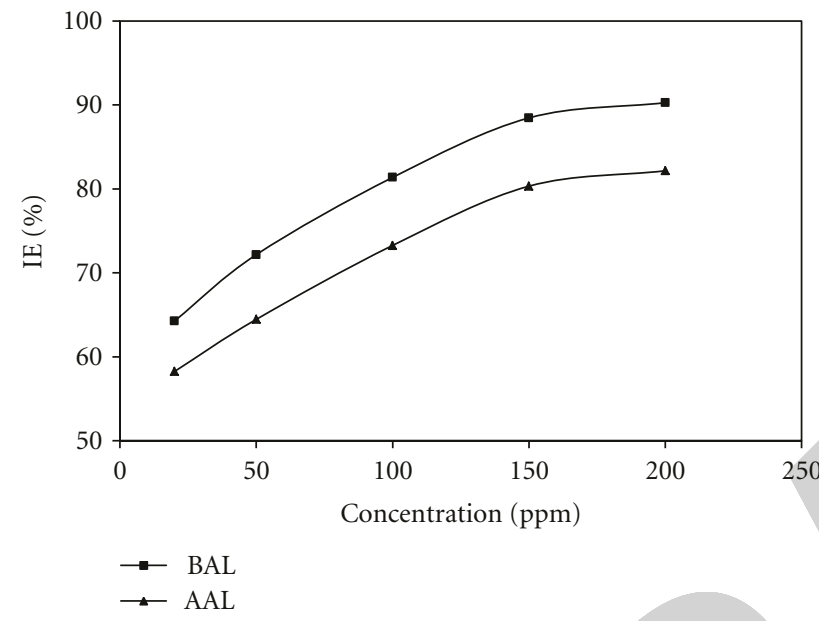

FIGURE 1: Variation of inhibition efficiency with concentration in presence of AAL and BAL.
3.1.4. Kinetic Study. The apparent activation energy $\left(E_{a}\right)$ was calculated by using Arrhenius equation:

$$
\log k=-\frac{E_{a}}{2.303 R T}+\log A,
$$

where $k$ is rate of corrosion, $E_{a}$ is the apparent activation energy, $R$ is the universal gas constant, $T$ is absolute temperature, and $A$ is the Arrhenius preexponential factor. By plotting $\log k$ against $1 / T$ the values of activation energy $\left(E_{a}\right)$ have been calculated $\left(E_{a}=-(\right.$ Slope $\left.) \times 2.303 \times R\right)$ (Figure 3). Activation energy for $\mathrm{N} 80$ steel in $15 \% \mathrm{HCl}$ increases in presence of inhibitors. The $E_{a}$ values for AAL and BAL were found to be $57.6 \mathrm{~kJ} / \mathrm{mol}, 68.7 \mathrm{~kJ} / \mathrm{mol}$, respectively, (Table $3)$, which are higher than the $E_{a}$ value for blank solution $(38.4 \mathrm{~kJ} / \mathrm{mol})$.

The values of entropy of activation $\left(\Delta S^{*}\right)$ and enthalpy of activation $\left(\Delta H^{*}\right)$ were calculated by using the formula:

$$
k=\left(\frac{R T}{N h}\right) \exp \left(\frac{\Delta S^{*}}{R}\right) \exp \left(\frac{\Delta H^{*}}{R T}\right),
$$

TABLE 1: Corrosion inhibition of $\mathrm{N} 80$ steel in $15 \% \mathrm{HCl}$ in presence and absence of inhibitors AAL and BAL at different concentration.

\begin{tabular}{lcccc}
\hline $\begin{array}{l}\text { Conc. } \\
(\mathrm{ppm})\end{array}$ & $\begin{array}{c}\text { CR } \\
\text { (mpy) }\end{array}$ & \%IE & $\begin{array}{c}\text { BAL } \\
\text { (mpy) }\end{array}$ & \%IE \\
\hline 0 & 9.55 & - & 9.55 & - \\
10 & 3.98 & 58.2 & 3.41 & 64.2 \\
20 & 3.39 & 64.4 & 2.66 & 72.1 \\
50 & 2.55 & 73.3 & 1.78 & 81.3 \\
100 & 1.88 & 80.3 & 1.10 & 88.4 \\
150 & 1.70 & 82.2 & 0.93 & 90.2 \\
\hline
\end{tabular}

in Table 2. The observation depicts that rate of corrosion increases with increase in temperature. This may be due to the fact that at higher temperature the metal organic complex layer dissociates leaving a porous diffused film, which is responsible for corrosion [12].

3.1.3. Adsorption Isotherms. To determine the adsorption mode, various isotherms were tested, and Langmuir adsorption isotherm was found to be best, which gives a straight line graph for the plot of $\log (\theta / 1-\theta)$ verses logarithmic concentration of inhibitors (Figure 2). where $k$ is rate of corrosion, $h$ is Planks constant, $N$ is Avogadro's number, $\Delta S^{*}$ is the entropy of activation, and $\Delta H^{*}$ is the enthalpy of activation. A plot of $\log (k / T)$ verses $1 / T$ (Figure 4 ) should give a straight line, with a slope of $\left(-\Delta H^{*} / 2.303 R\right)$ and a intercept of $[\log (R / N h)+$ $\left.\Delta S^{*} / 2.303 R\right]$, from which the values of $\Delta S^{*}$ and $\Delta H^{*}$ can be calculated (Table 3 ). The $\Delta H^{*}$ values for AAL and BAL were found to be as $-62.1 \mathrm{~kJ} / \mathrm{mol}$ and $-69.4 \mathrm{~kJ} / \mathrm{mol}$, respectively, that revealed the exothermic nature of corrosion reaction. $\Delta S^{*}$ values were found to be $-32.5 \mathrm{~J} / \mathrm{mol}$ and $-22.5 \mathrm{~J} / \mathrm{mol}$ for AAL and BAL, respectively (Table 3 ).

The average value for free energy of adsorption $\left(\Delta G_{\text {ads }}\right)$ were calculated using the following equation:

$$
K=\frac{1}{55.5} \exp \left(\frac{-\Delta G_{\mathrm{ads}}}{R T}\right),
$$

where $\theta$ is degree of coverage on metal surface, $C$ is concentration of inhibitors in $\mathrm{moll}^{-1}, R$ is molar gas constant in $\mathrm{JK}^{-1} \mathrm{moL}^{-1}$, and $T$ is temperature. The value of 55.5 in the above equation is the concentration of water in the solution in mole/litre. The equilibrium constant $(K)$ has been replaced by the equation

$$
K=\frac{\theta}{(1-\theta) C} .
$$

By plotting $\log K$ against $1 / T$ the value of $\Delta G_{\text {ads }}$ can be calculated $\left(\Delta G_{\mathrm{ads}}=-2.303 \times R \times\right.$ Slope $)$ from the slope of 
TABLE 2: Corrosion parameters in absence and in presence of AAL and BAL at different temperatures.

\begin{tabular}{|c|c|c|c|c|c|c|}
\hline \multirow{2}{*}{ Temperature (K) } & \multicolumn{2}{|c|}{ Blank } & \multicolumn{2}{|c|}{ AAL } & \multicolumn{2}{|c|}{ BAL } \\
\hline & CR (mpy) & $\mathrm{IE} \%$ & CR (mpy) & $\mathrm{IE} \%$ & CR (mpy) & IE $\%$ \\
\hline 298 & 9.55 & - & 1.70 & 82.2 & 0.93 & 90.2 \\
\hline 303 & 12.09 & - & 2.63 & 78.2 & 1.79 & 85.1 \\
\hline 313 & 19.27 & - & 4.87 & 74.7 & 4.21 & 78.1 \\
\hline 323 & 30.42 & - & 10.51 & 65.4 & 9.01 & 70.3 \\
\hline 333 & 48.94 & - & 20.09 & 58.9 & 18.31 & 62.5 \\
\hline
\end{tabular}

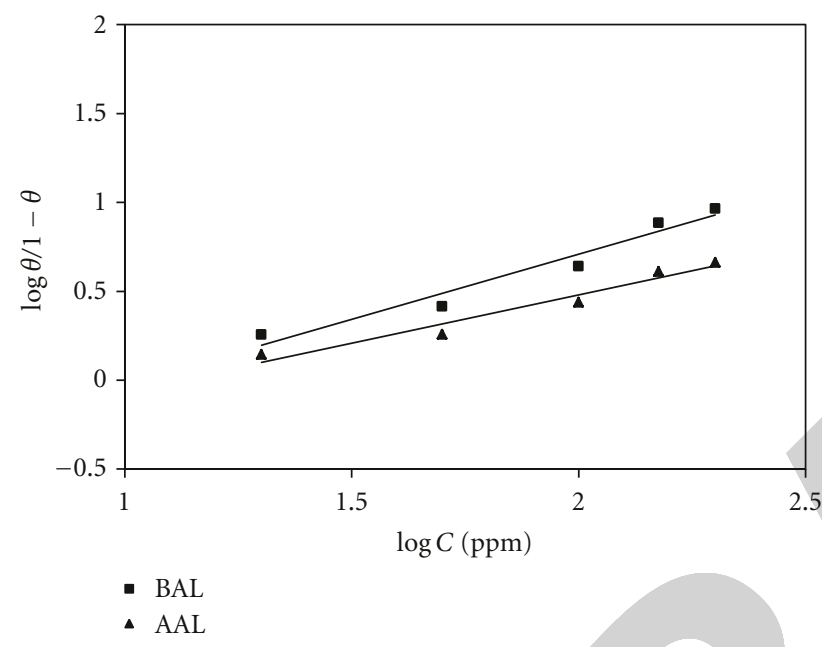

FIGURE 2: Langmuir adsorption isotherm in presence of AAL and BAL.

the straight line obtained (Figure 5). The values of free energy of adsorption $\left(\Delta G_{\text {ads }}\right)$ for AAL and BAL were found to be $-32.2 \mathrm{~kJ} / \mathrm{mol}$ and $-36.7 \mathrm{~kJ} / \mathrm{mol}$, respectively (Table 3 ). Values of $\Delta G_{\text {ads }}$ around $-20 \mathrm{~kJ} / \mathrm{mol}$ or lower are consistent with the electrostatic interaction between charged organic molecules and the charged metal surface (physisorption); those around $-40 \mathrm{~kJ} / \mathrm{mol}$ or higher involve charge sharing or transfer from the organic molecules to the metal surface to form a coordinate type of bond (chemisorptions). The value of $\Delta G_{\text {ads }}$ for AAL and BAL that was found to be $-32.2 \mathrm{~kJ} / \mathrm{mol}$ and $-36.7 \mathrm{~kJ} / \mathrm{mol}$ which is less than $-40 \mathrm{~kJ} / \mathrm{mol}$ indicated that in addition to electrostatic interaction, there may be some other interactions [13]. Lebrini et al. [14] studied some triazole derivatives as corrosion inhibitors of mild steel in $1 \mathrm{M} \mathrm{HClO}_{4}$. The Gibbs free energy of adsorption of these molecules were reported to be around $-34 \mathrm{~kJ} / \mathrm{mol}$. They concluded that the adsorption mechanism of these molecules on steel involved two types of interactions, chemisorptions, and physisorption. Similar conclusion was found by Ozcan [15], who studied the use of cystine as a corrosion inhibitor on mild steel in sulfuric acid. Thus, adsorption of studied inhibitors at the surface of N80 steel is not pure physisorption but it is combination of physisorption as well as chemisorptions.

3.2. Potentiodynamic Polarization Study. Figures 6 and 7 show the polarization curves of N80 steel in $15 \% \mathrm{HCl}$ solution in absence and presence of 10,50, and $150 \mathrm{ppm}$ of inhibitors

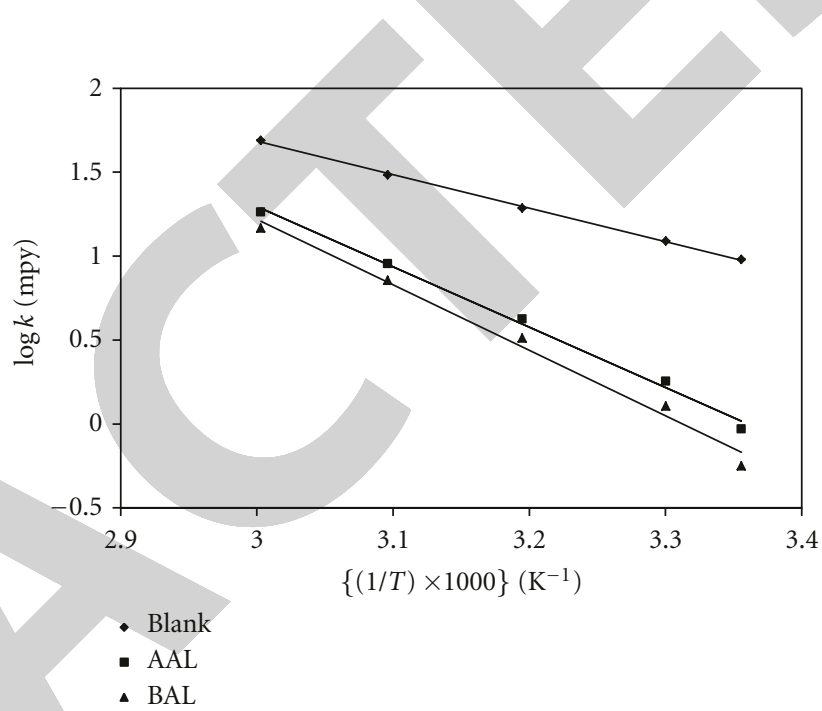

FIGURE 3: Arrhenius plot for the corrosion of N80 steel in 15\% HCI in presence and in absence of AAL and BAL.

AAL and BAL, respectively. The nature of the polarization curves remains almost same in absence and presence of both the inhibitors but in presence of inhibitors the curves shifted towards the lower current density as compared to the blank. The shift in current density towards lower current density in presence of inhibitors increases on increasing the concentration of the inhibitors. The electrochemical corrosion parameters including corrosion current densities $\left(I_{\text {corr }}\right)$, corrosion potential $\left(E_{\text {corr }}\right)$, cathodic Tafel slope $\left(\beta_{c}\right)$, anodic Tafel slope $\left(\beta_{a}\right)$, and inhibition efficiency obtained from the polarization curves of AAL and BAL are presented in Table 4. It is clear from the Figures 6 and 7 that with the increase of inhibitors concentration both anodic and cathodic currents were inhibited.

It is apparent from the Table 4 that $I_{\text {corr }}$ decreases considerably in the presence of both the inhibitors, and \%IE increases with the increase in the inhibitor concentration, due to the increase in the blocked fraction of the electrode surface by adsorption. The value of anodic and cathodic Tafel slopes increases in presence of both the inhibitors as compared to the blank solution. A minor shift in $E_{\text {corr }}$ values towards the negative direction was obtained in presence of both the inhibitors, indicating mixed nature of the inhibitors.

3.3. Electrochemical Impedance Spectroscopy. Nyquist plots of $\mathrm{N} 80$ steel in $15 \% \mathrm{HCl}$ in the presence and absence of 
TABLE 3: Thermodynamic parameter in absence and in presence of AAL and BAL.

\begin{tabular}{lcccc}
\hline Inhibitor & $\Delta H^{*}(\mathrm{~kJ} / \mathrm{mol})$ & $E_{a}(\mathrm{~kJ} / \mathrm{mol})$ & $\Delta G_{\text {ads }}(\mathrm{kJ} / \mathrm{mol})$ & - \\
\hline Blank & - & 38.4 & -32.2 & $-3 S^{*}(\mathrm{~J} / \mathrm{mol})$ \\
AAL & -62.1 & 57.6 & -36.7 & -2.5 \\
BAL & -69.4 & 68.7 & -2.5 \\
\hline
\end{tabular}

TABLE 4: Electrochemical corrosion parameters in absence and in presence of AAL and BAL at different concentration.

\begin{tabular}{|c|c|c|c|c|c|c|c|}
\hline \multirow{2}{*}{ Inhibitors } & \multirow{2}{*}{$\begin{array}{l}\text { Conc of inhibitors } \\
(\mathrm{ppm})\end{array}$} & \multicolumn{2}{|c|}{ Tafel slopes } & \multirow{2}{*}{$\begin{array}{l}I_{\text {corr }} \\
\left(\mu \mathrm{A} / \mathrm{cm}^{2}\right)\end{array}$} & \multirow{2}{*}{$E_{\text {corr }}(\mathrm{mV})$} & \multirow{2}{*}{$\% \mathrm{IE}$} & \multirow{2}{*}{$\begin{array}{l}\text { \%IE from } \\
\text { wt. loss }\end{array}$} \\
\hline & & $\beta_{a}\left(\mathrm{mV} \mathrm{dec}{ }^{-1}\right)$ & $\beta_{c}\left(\mathrm{mV} \mathrm{dec}^{-1}\right)$ & & & & \\
\hline Blank & - & 109 & 153 & 471 & -468 & - & - \\
\hline \multirow{3}{*}{ AAL } & 10 & 113 & 162 & 193 & 460 & 59.0 & 58.2 \\
\hline & 50 & 118 & 170 & 108 & -462 & 77.0 & 73.3 \\
\hline & 150 & 121 & 178 & 74 & -478 & 84.1 & 82.2 \\
\hline \multirow{3}{*}{ BAL } & 10 & 116 & 171 & 172 & -476 & 63.3 & 64.2 \\
\hline & 50 & 119 & 180 & 84 & -480 & 82.1 & 81.3 \\
\hline & 150 & 125 & 187 & 35 & -484 & 92.5 & 90.2 \\
\hline
\end{tabular}

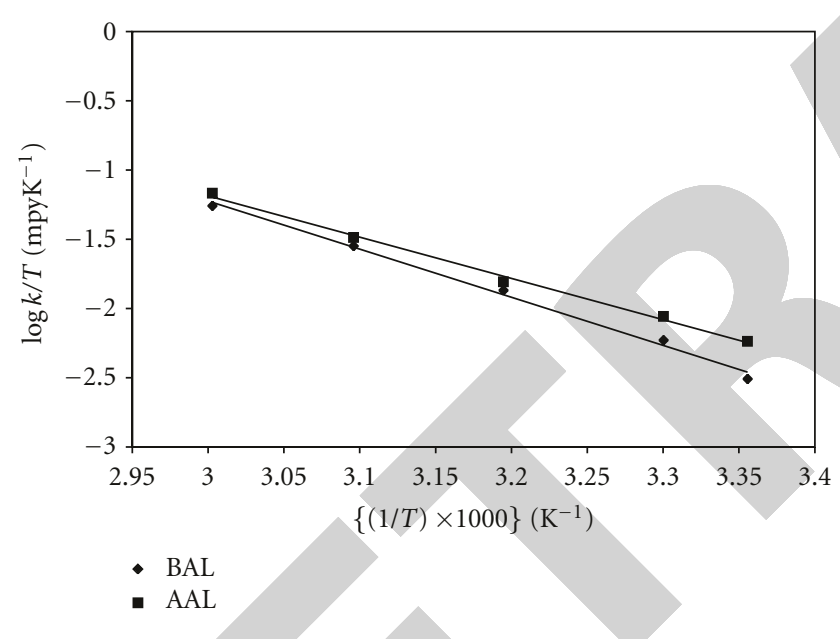

FIgUre 4: A plot of $\log k / T$ versus $1 / T$ in presence of AAL and BAL.

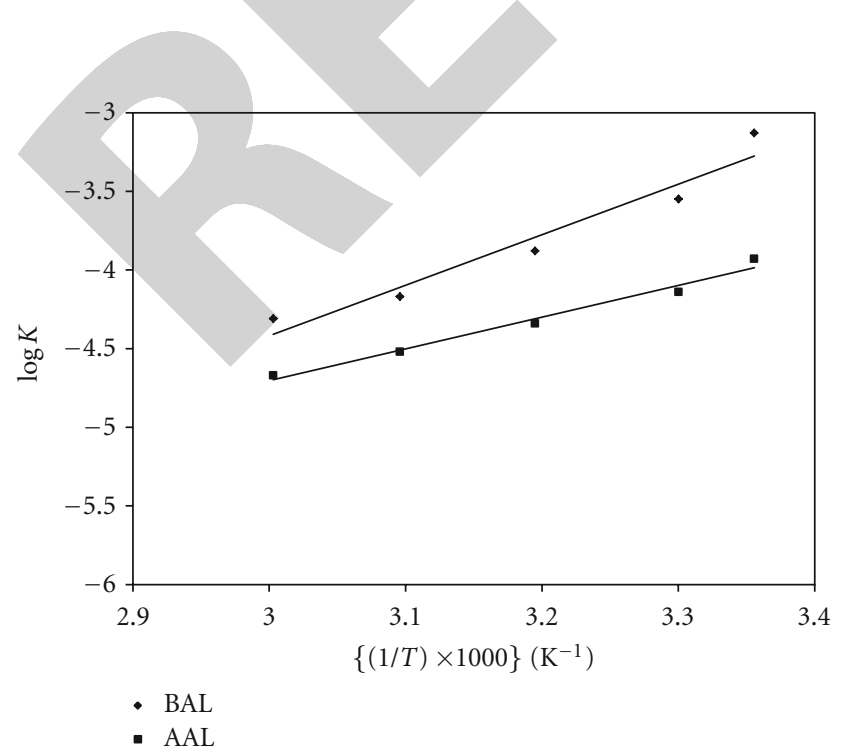

Figure 5: A plot of $\log K$ versus $1 / T$ in presence of AAL and BAL.

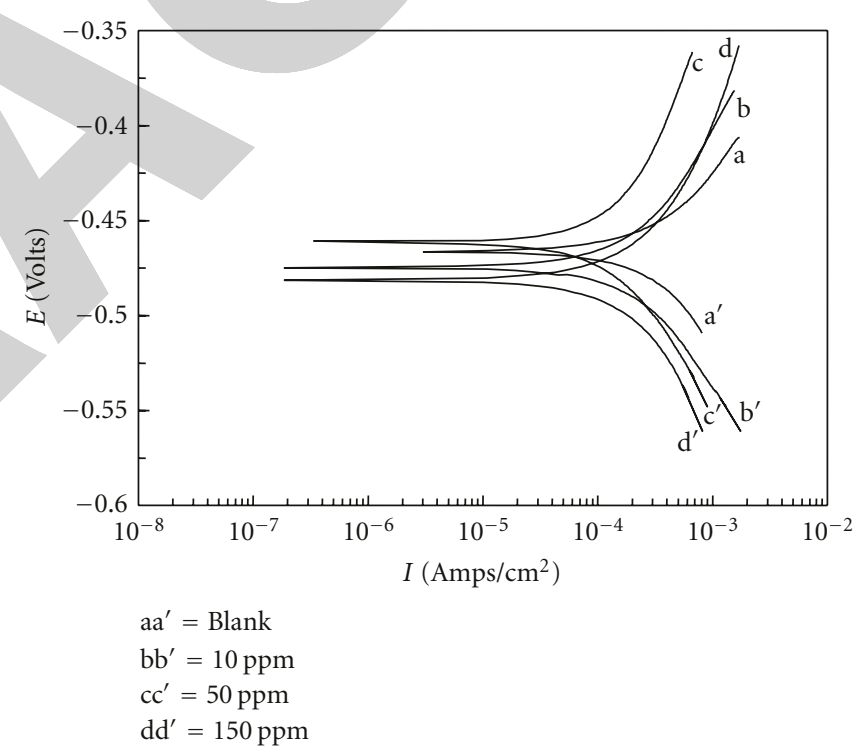

Figure 6: Potentiodynamic polarization curves for N80 steel in $15 \% \mathrm{HCl}$ in absence and in presence of AAL.

different concentrations $(10,50$, and $150 \mathrm{ppm})$ of $\mathrm{AAL}$ and BAL at $25 \pm 1^{\circ} \mathrm{C}$ are shown in the Figures 8 and 9 . All the Nyquist plots obtained were semicircle in nature, the diameter of the semicircles increases with increase in inhibitor concentration, and shape is maintained throughout the tested concentration, indicating that almost no change in the corrosion mechanism occurs due to inhibitor action. The electrochemical parameters $\left(R_{\mathrm{ct}}, C_{\mathrm{dl}}\right)$ calculated from the Nyquist plots by using the equivalent circuit (Figure 10) in presence and absence of inhibitors are presented in Table 5. Inspection of Table 5 reveals that $R_{\mathrm{ct}}$ values increase prominently while $C_{\mathrm{dl}}$ values tend to decrease with the increasing concentration of inhibitors, which suggest that inhibitors molecule function by adsorption on metal/solution 
TABLE 5: Electrochemical impedance parameters in absence and in presence of AAL and BAL.

\begin{tabular}{|c|c|c|c|c|}
\hline Inhibitors & Conc. (ppm) & $R_{\mathrm{ct}}\left(\Omega \mathrm{cm}^{2}\right)$ & $C_{\mathrm{dl}}\left(\mu \mathrm{F} \mathrm{cm}^{-2}\right)$ & IE\% \\
\hline Blank & - & 176 & 662 & - \\
\hline \multirow{3}{*}{ AAL } & 10 & 439 & 369 & 59.9 \\
\hline & 50 & 745 & 173 & 76.3 \\
\hline & 150 & 1006 & 145 & 82.5 \\
\hline \multirow{3}{*}{ BAL } & 10 & 505 & 286 & 65.1 \\
\hline & 50 & 998 & 165 & 82.3 \\
\hline & 150 & 2301 & 55 & 92.3 \\
\hline
\end{tabular}

The experimental results in the (Table 1) reveal that inhibition efficiency offered by AAL and BAL increases on increasing their concentration indicating that adsorption of inhibitors increases as concentration increases resulting in reduction of corrosion rate. It is clear for the Table 2 that the inhibition efficiency of both the inhibitors decreases on increasing the temperature. The decrease in efficiency at higher temperature may be due to desorption of inhibitors from the N80 steel surface at higher temperatures. The surface coverage data of AAL and BAL shows that both the inhibitors followed Langmuir adsorption isotherm indicating that adsorption is the root cause of corrosion inhibition.

The values of apparent activation energy $\left(E_{a}\right)$ in the inhibited solution were found to be higher as compared to that in the blank acid (Table 3). The increase in activation energy $E_{a}$ indicates the retardation in corrosion rate which could have occurred because of adsorption of the inhibitors at the surface of the metal. The higher value of $E_{a}$ in presence of both the inhibitors as compared to the blank solution also indicated that the dissolution of N80 steel was decreased by making a barrier by their adsorption on metal surface. The $\Delta H^{*}$ values for AAL and BAL were found to be as $-62.1 \mathrm{~kJ} / \mathrm{mol}$ and $-69.4 \mathrm{~kJ} / \mathrm{mol}$, respectively, that revealed the exothermic nature of corrosion reaction. $\Delta S^{*}$ values were found to be $-32.5 \mathrm{~J} / \mathrm{mol}$ and $-22.5 \mathrm{~J} / \mathrm{mol}$ for AAL and BAL, respectively (Table 3 ).

The value of $\Delta G_{\text {ads }}$ for $\mathrm{AAL}$ and BAL was found to be $-32.2 \mathrm{~kJ} / \mathrm{mol}$ and $-36.7 \mathrm{~kJ} / \mathrm{mol}$, respectively (Table 3 ). The negative values of $\Delta G_{\text {ads }}$ are consistent with the spontaneity of the adsorption process. Generally, the energy values of $-20 \mathrm{~kJ} / \mathrm{mol}$ or less negative are associated with an electrostatic interaction between charged molecules and charged metal surface, physisorption; those of $-40 \mathrm{~kJ} / \mathrm{mol}$ or more negative involve charge sharing or transfer from the inhibitor molecules to the metal surface to form a coordinate covalent bond, chemisorptions [16]. In present study, the $\Delta G_{\text {ads }}$ value obtained for both inhibitors on N80 steel in $15 \% \mathrm{HCl}$ solution was higher than $-20 \mathrm{~kJ} / \mathrm{mol}$ but less than $-40 \mathrm{~kJ} / \mathrm{mol}$ (Table 3); this indicates that the adsorption is neither typical physisorption nor typical hemisorptions but it is complex mixed type; that, is the adsorption of inhibitor molecules on the N80 steel surface in present study involves both physisorption and chemisorptions. The negative values medium in presence of $\mathrm{BAL}$ and $\mathrm{AAL}$, respectively, at the same magnifications. 


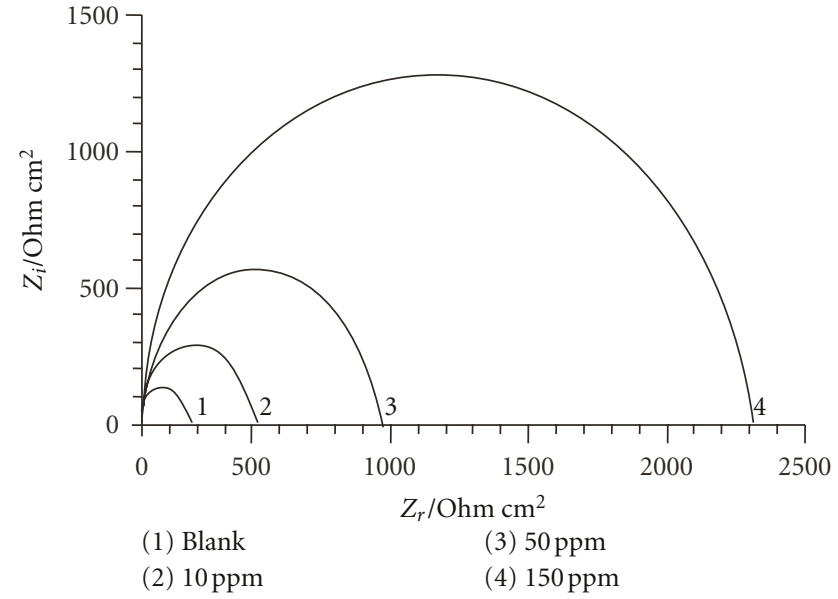

Figure 8: Nyquist plots of the corrosion of N80 steel in $15 \% \mathrm{HCl}$ without and with different concentration of BAL.

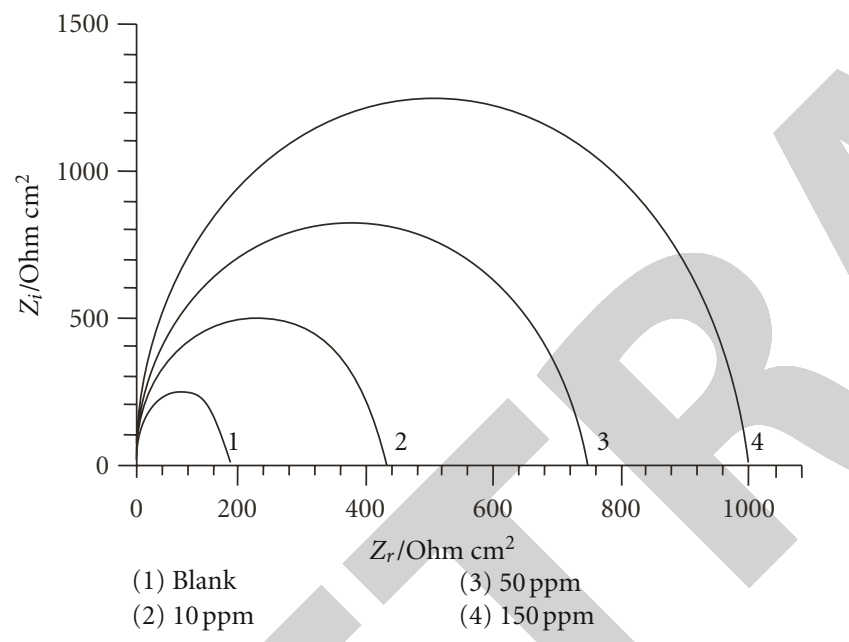

FIGURE 9: Nyquist plots of the corrosion of N80 steel in $15 \% \mathrm{HCl}$ without and with different concentration of AAL.

of $\Delta S^{*}$ obtained in the inhibited and uninhibited solutions suggest that the activated complex is the stage that determines the corrosion rate [17]. The negative values of the entropy change of activation $\left(\Delta S^{*}\right)$ for AAL and BAL also imply that the activated complex in the rate determining step represents an association rather than a dissociation step, indicating that a decrease in disordering takes place on going from reactants to the activated complex [18]. The negative value of enthalpy change of activation $\left(\Delta H^{*}\right)$ reflects the exothermic nature of activation of corrosion process.

The variation in the values of $\beta_{a}$ and $\beta_{c}$ in presence of both the inhibitors (Table 4 ) indicates that both the anodic and cathodic processes are controlled. The significant reduction in $I_{\text {corr }}$ at higher concentration level (150 ppm) indicated better inhibition performance at higher concentration. In $15 \% \mathrm{HCl}$ solution, the presence of AAL and BAL cause a minor shift in $E_{\text {corr }}$, which indicates that inhibitor molecules are mixed type inhibitors. Generally, if the displacement in $E_{\text {corr }}$ is $>85 \mathrm{mV}$ with respect to $E_{\text {corr }}$ in uninhibited solution,

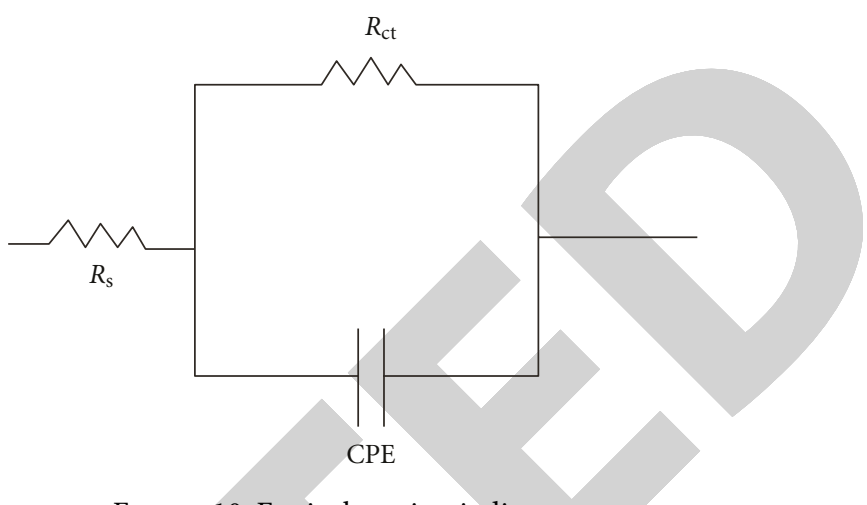

FIGURE 10: Equivalent circuit diagram.

the inhibitor can be seen as a cathodic or anodic type $[19,20]$. In our study the maximum displacement is $12 \mathrm{mV}$ in BAL and $10 \mathrm{mV}$ in AAL, which indicates that both inhibitors can be arranged as a mixed type inhibitor.

In EIS study an increase in $R_{\mathrm{ct}}$ value is observed with increasing the inhibitors concentration, suggesting that the charge transfer process is retarded due to decrease in the uncovered surface available for corrosion reaction. Due to the nonhomogeneity or roughness of the metal surface the observed semicircles of capacitive loops were depressed into the $\mathrm{Zi}$ which is often referred to as frequency dispersion [21]. It is worth mentioning that the double layer capacitance $\left(C_{\mathrm{dl}}\right)$ value is affected by imperfections of the surface [22]. The $C_{\mathrm{dl}}$ values were found to decrease with increase in concentration of inhibitors solutions. This behavior is generally seen for system where inhibition occurred due to the formation of a surface film by the adsorption of inhibitor on the metal surface [23]. Decrease in $C_{\mathrm{dl}}$, which can result from a decrease in local dielectric constant and/or an increase in the thickness of the electrical double layer, suggests that the inhibitor molecules act by adsorption at the metal/solution interface [24].

Figure 11(b) shows the SEM microphotographs of N80 steel (magnification 1000x) when exposed to $15 \% \mathrm{HCl}$ solution at room temperature in absence of inhibitors. Figure 11(b) shows that the steel surface appears to be very rough in absence of inhibitors. This is due to formation of uniform flake type corrosion products on the metal surface. No pitting and other separate phase are visible in microphotograph. Figures 11(c) and 11(d) are the microphotographs of the metal surface when exposed to the acid medium in presence of BAL and AAL, respectively, at the same magnifications. In comparison to the microphotograph of the steel surface without inhibitor the photographs of the exposed surface in presence of inhibitors are found to be covered with a semiglobular type protective film of compounds uniformly spread over the surface. The protective film is formed due to adsorption of the inhibitor molecules on the steel surface.

The inhibition efficiency afforded by AAL and BAL may be attributed to the presence of electron-rich $\mathrm{N}$ atoms of amino group. The inhibition efficiency of BAL is higher as compared to AAL due to presence of delocalized $\pi$-electrons and its bigger size. In the aqueous acidic solutions $\mathrm{AAL}$ 

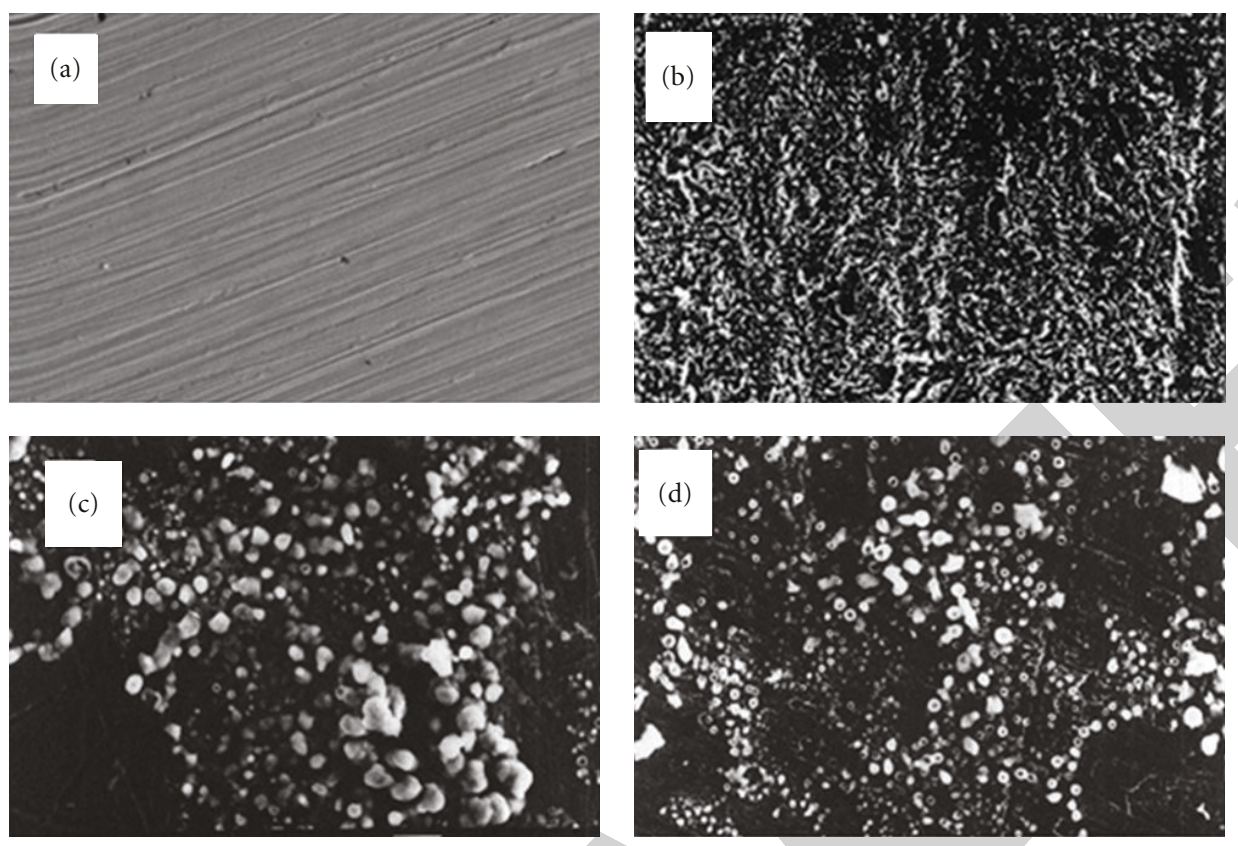

FIGURE 11: SEM of (a) polished sample; (b) sample in presence of $15 \%$ hydrochloric acid; (c) sample in presence of $150 \mathrm{ppm}$ of BAL; (d) sample in presence of $500 \mathrm{ppm}$ of AAL.

and BAL exist either as neutral molecules or in the form of protonated molecules (cations). These inhibitors may adsorb on the metal/acid solution interface by one and/or more of the following ways:

(i) electrostatic interaction of protonated inhibitors with already adsorbed chloride ions,

(ii) interaction between unshared electron pairs of heteroatoms and vacant $\mathrm{d}$ orbital of iron surface atoms.

Generally, two modes of adsorption could be considered. In one mode, the neutral inhibitors may be adsorbed on the surface of N80 steel through the chemisorptions mechanism, involving the displacement of water molecules from the N80 steel surface and the sharing electrons between the heteroatoms and iron. In another mode, since it is well known that the steel surface bears positive charge in acid solution [25], so it is difficult for the protonated inhibitors to approach the positively charged mild steel surface $\left(\mathrm{H}_{3} \mathrm{O}^{+} /\right.$metal interface $)$due to the electrostatic repulsion. Since chloride ions have a smaller degree of hydration, thus they could bring excess negative charges in the vicinity of the interface and favour more adsorption of the positively charged inhibitor molecules, and the protonated inhibitors adsorb through electrostatic interactions between the positively charged molecules and the negatively charged metal surface. Thus there is a synergism between adsorbed $\mathrm{Cl}^{-}$ions and protonated inhibitors. Experimental data reveals that \%IE inhibitors are in the order BAL > AAL.

\section{Conclusion}

AAL and BAL both act as good corrosion inhibitors for corrosion of $\mathrm{N} 80$ steel in $15 \% \mathrm{HCl}$ solution. The inhibition efficiency values increase with the increase in inhibitors concentration but decrease with increasing temperature for corrosion of $\mathrm{N} 80$ steel in $15 \% \mathrm{HCl}$. The adsorption of the AAL and BAL on N80 steel surface obeys Langmuir adsorption isotherm. Variation in the values of $\beta_{a}$ and $\beta_{c}$ (Tafel slopes) and shift in the values of corrosion potential $\left(E_{\text {corr }}\right)$ indicate that both the tested inhibitors are mixed type inhibitors; EIS measurements show that charge transfer resistance $\left(R_{\mathrm{ct}}\right)$ increases and double layer capacitance $\left(C_{\mathrm{dl}}\right)$ decreases in presence of inhibitors. The SEM of the inhibited metal surface suggested the adsorption of the inhibitor molecules on the surface of N80 steel.

\section{Acknowledgments}

Financial assistance from Indian School of Mines Dhanbad under the "Faculty Research Scheme" to M. Yadav is gratefully acknowledged.

\section{References}

[1] G. W. Poling, "Infrared studies of protective films formed by acetylenic corrosion inhibitors," Journal of The Electrochemical Society, vol. 114, pp. 1209-1214, 1967.

[2] K. D. Neemla, R. C. Saxena, and A. Jayaraman, "Corrosion inhibitor studies on steels in hydrochloric acid," Corrosion Prevention and Control, vol. 6, pp. 69-76, 1992.

[3] W. W. Frenier, F. B. Growcock, and V. R. Lopp, " $\alpha$-alkenylphenones-a new class of acid corrosion inhibitors," Corrosion, vol. 44, no. 9, pp. 590-598, 1988.

[4] W. W. Frenier, Eur. Patent, 047400, 1972.

[5] A. 1. Cizek, U.S. Patent 4997040, 1991. 
[6] R. F. Monroe, C. H. Kuchera, and B. D. Oates, U.S. Patent, $3007454,1963$.

[7] S. Ghareba and S. Omanovic, "Interaction of 12-aminododecanoic acid with a carbon steel surface: towards the development of "green" corrosion inhibitors," Corrosion Science, vol. 52, no. 6, pp. 2104-2113, 2010.

[8] A. R. Sathiya Priya, V. S. Muralidharan, and A. Subramania, "Development of novel acidizing inhibitors for carbon steel corrosion in $15 \%$ boiling hydrochloric acid," Corrosion, vol. 64 , no. 6, pp. 541-552, 2008.

[9] P. Bommersbach, C. Alemany-Dumont, J. P. Millet, and B. Normand, "Hydrodynamic effect on the behaviour of a corrosion inhibitor film: characterization by electrochemical impedance spectroscopy," Electrochimica Acta, vol. 51, no. 19, pp. 4011-4018, 2006.

[10] Q. Qu, Z. Hao, L. Li, W. Bai, Y. Liu, and Z. Ding, "Synthesis and evaluation of Tris-hydroxymethyl-(2-hydroxybenzylidenamino)-methane as a corrosion inhibitor for cold rolled steel in hydrochloric acid," Corrosion Science, vol. 51, no. 3, pp. 569-574, 2009.

[11] M. Bodanszky, Peptide Chemistry: A Practical Text Book, Springer, Berlin, Germany, 1988.

[12] I. N. Putolova, S. A. Balezin, and V. P. Barannik, Metallic Corrosion Inhibitors, Pergamon Press, New York, NY, USA, 1960.

[13] M. Behpour, S. M. Ghoreishi, N. Soltani, M. Salavati-Niasari, M. Hamadanian, and A. Gandomi, "Electrochemical and theoretical investigation on the corrosion inhibition of mild steel by thiosalicylaldehyde derivatives in hydrochloric acid solution," Corrosion Science, vol. 50, no. 8, pp. 2172-2181, 2008.

[14] M. Lebrini, M. Traisnel, M. Lagrenée, B. Mernari, and F. Bentiss, "Inhibitive properties, adsorption and a theoretical study of 3,5-bis(n-pyridyl)-4-amino-1,2,4-triazoles as corrosion inhibitors for mild steel in perchloric acid," Corrosion Science, vol. 50, no. 2, pp. 473-479, 2008.

[15] M. Ozcan, "AC impedance measurement of cystine adsorption at mild steel/sulfuric acid interface as corrosion inhibitor," Journal of Solid State Electrochemistry, vol. 12, pp. 1653-1661, 2008.

[16] I. Dehri and M. Özcan, "The effect of temperature on the corrosion of mild steel in acidic media in the presence of some sulphur-containing organic compounds," Materials Chemistry and Physics, vol. 98, no. 2-3, pp. 316-323, 2006.

[17] S. S. Al-Juaid, "Inhibition of corrosion of carbon steel 1018 in acid medium with ethoxylated aliphatic alcohols," Chemistry and Technology of Fuels and Oils, vol. 47, no. 1, pp. 58-65, 2011.

[18] O. Olivares, N. V. Likhanova, B. Gómez et al., "Electrochemical and XPS studies of decylamides of $\alpha$-amino acids adsorption on carbon steel in acidic environment," Applied Surface Science, vol. 252, no. 8, pp. 2894-2909, 2006.

[19] H. Ashassi-Sorkhabi, M. R. Majidi, and K. Seyyedi, "Investigation of inhibition effect of some amino acids against steel corrosion in $\mathrm{HCl}$ solution," Applied Surface Science, vol. 225, no. 1-4, pp. 176-185, 2004.

[20] X. Li, S. Deng, and H. Fu, "Synergism between red tetrazolium and uracil on the corrosion of cold rolled steel in $\mathrm{H}_{2} \mathrm{SO}_{4}$ solution," Corrosion Science, vol. 51, no. 6, pp. 1344-1355, 2009.

[21] M. Lebrini, M. Lagrenée, H. Vezin, M. Traisnel, and F. Bentiss, "Experimental and theoretical study for corrosion inhibition of mild steel in normal hydrochloric acid solution by some new macrocyclic polyether compounds," Corrosion Science, vol. 49, no. 5, pp. 2254-2269, 2007.
[22] J. R. Macdonald, W. B. Johnson, and J. R. Macdonald, Eds., Impedance Spectroscopy, John Wiley \& Sons, New York, NY, USA, 1987.

[23] I. L. Rosenfield, Corrosion Inhibitors, McGraw-Hill, New York, NY, USA, 1981.

[24] M. MaCafferty and N. Hackerman, "Double layer capacitance of iron and corrosion inhibition with polymethylene diamines," Journal of The Electrochemical Society, vol. 119, pp. 146-154, 1972.

[25] G. N. Mu, T. P. Zhao, M. Liu, and T. Gu, "Effect of metallic cations on corrosion inhibition of an anionic surfactant for mild steel," Corrosion, vol. 52, no. 11, pp. 853-856, 1996. 